\title{
Good Corporate Governance dan Intellectual Capital Sebagai Determinan Nilai Perusahaan
}

\author{
Indri Kartika \\ Eka Dwi Payana \\ Universitas Islam Sultan Agung Semarang \\ indri@unissula.ac.id \\ ekadwipayana248@gmail.com
}

\begin{abstract}
The value of the company is very important because a high value of the company will provide prosperity for shareholders and the company's prospects in the future. This study aims to find empirical evidence about the effect of Good Corporate Governance (GCG) on Firm's Value with Intellectual Capital (IC) as an intervening variable. GCG is calculated using GCG Score with certain criteria, IC is calculated using the VAIC method, and firm's value is calculated using Tobin's $Q$. The population in this study is manufacturing companies listed on the Indonesia Stock Exchange (BEI) for the 2016-2018 period. Sampling using purposive sampling method obtained as many as 225 samples data of manufacturing companies during the period 2016-2018. Data analysis techniques used multiple linear regression analysis and sobel tests using the SPSS 26 program. The results of this study indicate that good corporate governance has a positive and significant effect on intellectual capital, intellectual capital has a positive and significant effect on firm's value, good corporate governance has a positive and significant effect to firm's value, and intellectual capital is able to mediate the relationship between good corporate governance and firm's value.
\end{abstract}

Keywords: Good Corporate Governance, Intellectual Capital, GCG Score, VAIC, Tobin's Q, Firm's Value.

\begin{abstract}
ABSTRAK
Nilai perusahaan sangat penting karena dengan nilai perusahaan yang tinggi akan memberikan kesejahteraan bagi para pemegang saham dan prospek perusahaan di masa yang akan datang. Penelitian ini bertujuan untuk menemukan bukti empiris mengenai pengaruh Good Corporate Governance (GCG) terhadap Nilai Perusahaan dengan Intellectual Capital (IC) sebagai variabel intervening. GCG dihitung menggunakan GCG Score dengan kriteria-kriteria tertentu, IC dihitung menggunakan metode VAIC, dan nilai perusahaan dihitung menggunakan Tobin's Q. Populasi dalam penelitian ini adalah perusahaan manufaktur yang terdaftar di Bursa Efek Indonesia (BEI) periode 2016-2018. Pengambilan sampel menggunakan metode purposive sampling diperoleh sebanyak 225 sampel data perusahaan manufaktur selama periode 2016-2018. Teknik analisis data menggunakan analisis regresi linier berganda dan uji sobel dengan menggunakan program SPSS 26. Hasil penelitian ini menunjukkan bahwa good corporate governance berpengaruh positif dan signifikan terhadap intellectual capital, intellectual capital berpengaruh positif dan signifikan terhadap nilai perusahaan, good corporate governance berpengaruh positif dan signifikan terhadap nilai perusahaan, dan intellectual capital mampu memediasi hubungan good corporate governance dengan nilai perusahaan.
\end{abstract}

Kata Kunci: Good Corporate Governance, Intellcetual Capital, GCG Score, VAIC, Tobin's Q, Nilai Perusahaan.

Good Corporate Governance dan Intellectual Capital Sebagai Determinan Nilai PerusahaanListiyowati, lin Indri Kartika \& Eka Dwi Payana Universitas Islam Sultan Agung Semarang 


\section{PENDAHULUAN}

Berdirinya sebuah perusahaan memiliki tujuan tertentu, salah satunya yaitu memaksimalkan nilai perusahaannya agar bisa tetap bersaing dalam dunia bisnis pada era sekarang yang semakin kompetitif. Nilai perusahaan sangat penting karena dengan nilai perusahaan yang tinggi akan memberikan kesejahteraan para pemegang saham (Maryanto, 2017). Nilai perusahaan dapat diukur melalui beberapa aspek salah satunya yaitu harga pasar saham yang mencerminkan penilaian investor atas setiap ekuitas yang dimiliki perusahaan. Hal ini dikarenakan semakin tinggi harga pasar saham maka nilai perusahaan juga tinggi, sehingga akan meningkatkan kepercayaan investor mengenai posisi perusahaan saat ini dan pertumbuhan perusahaan dimasa mendatang. Harga saham perusahaan manufaktur yang dilihat melalui harga saham penutupan tidak konsisten meningkat tiap tahunnya. Nilai perusahaan yang tidak konsisten terjadi karena adanya faktor- faktor yang dapat mempengaruhinya, yaitu good corporate governance. Good corporate governance merupakan sebuah konsep yang menjelaskan aturan yang mengatur hubungan antara para pemegang saham, manajer, direksi, maupun stakeholder lainnya yang berkaitan dengan proses, hak maupun kewajiban mereka yang dapat berfungsi sebagai sarana untuk menentukan teknik monitoring.

Penelitian-penelitian terdahulu memberikan hasil yang belum konsisten. Penelitian sebelumnya yang dilakukan oleh Herawaty (2008); Randy \& Juniarti (2013); Gwenda \& Juniarti (2013); Muryati \& Suardikha (2014); serta Maryanto (2017) menyatakan good corporate governance berpengaruh positif signifikan terhadap nilai perusahaan, sedangkan penelitian yang dilakukan Mutmainah (2015) serta Alfinur (2016) menyatakan bahawa good corporate governance berpengaruh negatif signifikan terhadap nilai perusahaan.

Perbedaan hasil penelitian tersebut mendorong untuk dilakukan penelitian kembali hubungan antara good corporate governance dan nilai perusahaan, dengan menambahkan intellectual capital sebagai variabel intervening.

Intellectualcapitaldiakui sebagai aset perusahaanyang mampu menghasilkan nilaitambah dan keunggulan kompetitif dalam mengelola aset perusahaan sehingga perusahaan dapat bertahan di lingkungan bisnis yang sedang berkembang pesat (Indah \& Handayani, 2017). Peningkatan intellectual capital menjadi hal penting dalam ekonomi yang berbasis pengetahuan saat ini dengan menerapkan konsep manajemen pengetahuan yang bertugas mencari informasi mengenai bagaimana cara memilih, mengelola, dan memanfaatkan sumber daya agar lebih efektif dan efisien (Hartati, 2014). Intellectual capital yang baik juga memiliki peran dalam penciptaan nilai perusahaan, dimana perusahaan yang mengelola IC secara maksimal dapat mencerminkan bahwa perusahaan tersebut memiliki keunggulan kompetitif sehingga mampu menciptakan nilai perusahaan yang tinggi.

Hasil penelitian ini diharapkan memberikan kontribusi untuk memecahkan perbedaan hasil penelitian terdahulu dan memberi sumbangan bagi pengembangan ilmu khususnya intellectual capital.

\section{LANDASAN TEORI}

\section{Agency Theory}

Menurut Jensen \& Meckling (1976) agency theory menjelaskan adanya hubungan kontrak kerja yang 
melibatkan dua pihak antara pihak prinsipal dengan pihak agen untuk melaksanakan suatu pekerjaan atas nama prinsipal, yang melibatkan agen dalam pengambilan keputusan. Adanya pemisahan kepemilikan antara pemilik (prinsipal) dan pengelola atau manajer (agen) akan menyebabkan potensi konflik keagenan yang biasa disebut dengan agency conflict (Gwenda \& Juniarti, 2013). Untuk mengurangi asimetri informasi dan perbedaan kepentingan dibutuhkan sebuah mekanisme yaitu corporate governance sehingga dapat menjadikan perusahaan yang lebih sehat. Mekanisme corporate governance pada perusahaan bertujuan untuk menumbuhkan pengendalian yang baik dan mencegah adanya penyimpangan atau tindak kecurangan yang dilakukan oleh pihak pengelola perusahaan (Hartati, 2014).

\section{Resources Based Theory (RBT)}

Pelopor pertama Resources Based theory adalah Penrose (1959) yang menyatakan bahwa sumber daya yang dimiliki perusahaan akan berbeda atau bersifat heterogen, dimana setiap perusahaan memiliki karakter khusus dan unik pada sumber daya perusahaan. Berdasarkan Resources Based theory perusahaan memiliki keunggulan dalam bersaing dan perusahaan mampu memiliki kinerja jangka panjang yang lebih baik dengan sumber daya yang dimiliki sehingga tidak mudah ditiru atau digantikan. Pengelolaan sumber daya dengan baik yang berupa intellectual capital dapat menciptakan keunggulan bersaing perusahaan yang nantinya dapat memberikan nilai tambah bagi perusahaan sehingga berpengaruh terhadap pertumbuhan perusahaan dan meningkatkan nilai pasar perusahaan tersebut (Nizar \& Anwar, 2015).

\section{Pengembangan Hipotesis}

\section{Pengaruh Good Corporate Governance terhadap Intellectual Capital}

Good corporate governance berfungsi sebagai pengendali dan mencegah adanya penyimpangan yang dilakukan oleh pihak pengelola perusahaan dalam menjalankan kegiatan operasional. Salah satu komponen corporate governance yaitu dewan komisaris dibantu oleh komite audit memiliki tanggung jawab untuk mengawasi dan mengendalikan tindakan yang dilakukan pihak manajemen termasuk dalam mengelola intellectual capital Handoko \& Fuad (2013). Dewan direksi bertugas untuk mengelola perusahaan dengan memanfaatkan intellectual capital yang dimiliki. Pengendalian internal yang diterapkan oleh perusahaan yang selalu dimonitoring oleh internal auditor mendorong manajemen untuk selalu mengelola perusahaan dengan baik. Dengan ini, penerapan GCG akan mendorong dan mengendalikan manajemen untuk menciptakan, mengelola, dan meningkatkan intellectual capital perusahaan, dimana intellectual capital sangat penting bagi perusahaan dalam menciptakan nilai dan keunggulan kompetitif perusahaan.

Hal tersebut sesuai dengan hasil penelitian Noventa (2016) bahwa good corporate governance berpengaruh positif dan signifikan terhadap intellectual capital. Berdasarkan uraian diatas, maka dapat dirumuskan hipotesis sebagai berikut.

H1 : Good corporate governance berpengaruh positif dan signifikan terhadap intellectual capital

Good Corporate Governance dan Intellectual Capital Sebagai Determinan Nilai PerusahaanListiyowati, lin 


\section{Pengaruh Intellectual Capital terhadap Nilai Perusahaan}

Menurut Sunarsih \& Mendra (2019) ketika perusahaan mempunyai kemampuan tinggi dalam mengelola intellectual capital nya, perusahaan akan mampu meningkatkan kompetensi dan keunggulan kompetitifnya, sehingga kegiatan operasional perusahaan akan meningkat. Pada akhirnya laba perusahaan juga mengalami peningkatan. Laba yang terus bertumbuh akan menarik investor karena deviden yang diterima semakin meningkat. Semakin tinggi intellectual capital maka semakin tinggi pula nilai perusahaan karena investor dapat menangkap sinyal dari perusahaan melalui intellectual capital dan menggunakan informasi tersebut sebagai bahan pertimbangan dalam mengambil keputusan investasi. Informasi yang disampaikan perusahaan melalui intellectual capital juga dapat mengurangi asimetri informasi sehingga mempermudah para investor mengetahui prospek perusahaan di masa yang akan datang.

Hal tersebut sejalan dengan penelitian yang dilakukan Maryanto (2017); Juwita \& Angela (2016) serta Awaliyah \& Safriliana (2017) bahwa komponen intellectual capital memiliki pengaruh positif dan signifikan terhadap nilai perusahaan, Berdasarkan uraian diatas, maka dapat dirumuskan hipotesis sebagai berikut.

\section{H2: Intellectual capital berpengaruh positif dan signifikan terhadap nilai perusahaan}

\section{Pengaruh Good Corporate Governance terhadap Nilai Perusahaan}

Perusahaan yang mempunyai good corporate governance yang bagus dapat dilihat pada perusahaan yang menerapkan GCG sesuai dengan prinsip- prinsip GCG dengan benar, dimana peran manajemen dalam menerapkan corporate governance untuk meminimalisir kemungkinan tindakan yang dapat merugikan para pemegang saham. Hal itu akan berdampak pada nilai perusahaan, karena tidak ada risiko manajemen untuk menguntungkan kepentingan pribadinya dengan kata lain pihak manajemen sudah bertindak sesuai keinginan prinsipal (Gwenda \& Juniarti, 2013). Menurut (Handayani, 2018) GCG berpengaruh positif terhadap nilai perusahaan, apabila sebuah perusahaan menerapkan tata kelola dengan baik maka dianggap memiliki nilai yang berarti perusahaan tersebut berharga dan memiliki prospek di masa depan.

Hal tersebut sejalan dengan hasil penelitian Randy \& Juniarti (2013); Maryanto (2017); serta Gwenda \& Juniarti (2013) bahwa good corporate governance memiliki pengaruh positif dan signifikan terhadap nilai perusahaan. Berdasarkan uraian diatas, maka dapat dirumuskan hipotesis sebagai berikut.

\section{H3 : Good corporate governance berpengaruh positif dan signifikan terhadap Nilai Perusahaan}

\section{METODE PENELITIAN}

\section{Populasi dan Sampel}

Populasi dalam penelitian ini adalah perusahaan manufaktur yang terdaftar di Bursa Efek Indonesia (BEI) tahun 2016-2018. Metode pengambilan sampel menggunakan teknik purposive sampling. Metode ini digunakan untuk menentukan sampel yang akan diambil dengan pertimbangan atau criteria tertentu. Adapun kriteria yang digunakan dalam sampel penelitian ini adalah : 1) Perusahaan manufaktur yang menyajikan laporan keuangan dan laporan tahunan berturut-turut untuk periode yang berakhir 31 Desember selama tahun 2016-2018 2) Laporan keuangan disajikan dalam mata uang rupiah (Rp) 3) Perusahaan dengan ekuitas 
positif selama periode 2016-2018 dan 4) Perusahaan memiliki kelengkapan data laporan keuangan dan data yang terkait dengan variabel penelitian. Total perusahaan yang diperoleh terdapat 85 sampel perusahaan pertahun dari 173 populasi.

\section{Variabel dan Pengukuran Variabel Nilai Perusahaan}

Menurut Darmadji \& Fakhruddi (2001) nilai perusahaan merupakan ukuran kinerja manajemen dalam mengelola perusahaan yang mampu memberikan kemakmuran yang optimal pada para pemegang saham dimana harga saham perusahaan mengalami peningkatan. Dalam penelitian ini nilai perusahaan akan diukur menggunakan Tobin's Q dengan rumus:

$$
\text { Tobin's } Q=\frac{E M V+D}{E B V+D}
$$

Keterangan :

$\mathrm{EMV}=$ Nilai pasar ekuitas

(harga penutupan saham di akhir tahun buku x banyaknya saham beredar)

D = Nilai buku dari total hutang EBV = Nilai buku dari total ekuitas

\section{Good Corporate Governance}

Menurut Randy \& Juniarti (2013) good corporate governance merupakan suatu konsep yang dijadikan untuk mengatasi masalah keagenan juga sebagai alat kontrol untuk memungkinkan terciptanya sistem pembagian keuntungan yang seimbang bagi stakeholder dan mampu meningkatkan efisiensi bagi perusahaan. Mengacu pada penelitian Black et al., (2006) dalam Randy \& Juniarti (2013), dalam penelitian ini good corporate governance diukur menggunakan proksi GCG score yang didalamnya terdiri dari lima subindex yang dijadikan sebagai acuan dalam menentukan skor diantaranya :

1. Shareholder Rights (subindexA)

2. Boards of Directors (subindex B)

3. Outside Directors (subindex C)

4. Audit Commite and Internal Auditor (subindexD)

5. Disclosure to Investors (subindex E)

Pengukuran GCG score dilakukan dengan masing-masing ukuran dalam subindex diberikan kriteria. Dimana masing-masing kriteria akan diberikan poin 1 jika terpenuhi, dan poin 0 jika tidak terpenuhi. Untuk mendapatkan total GCG score maka digunakan rumus sebagai berikut: 


$$
C G I=A+\frac{B+C}{2}+D+E
$$

Keterangan :

$\mathrm{CGI}=$ Corporate Governance Index

$\mathrm{A}=$ Shareholder Rights

B = Boards of Directors

$\mathrm{C}=$ Outside Directors

$\mathrm{D}=$ Audit Committee and Internal Auditor

$\mathrm{E} \quad=$ Disclosure to Investors

\section{Intellectual Capital}

Menurut Verawaty et al., (2017) intellectual capital merupakan sumber daya yang dimiliki perusahaan yang telah diformalisasikan, ditangkap, dan dimanfaatkan untuk mengelola asset yang nilainya lebih tinggi dan diyakini dapat berperan penting dalam peningkatan nilai perusahaan. dalam penelitian ini intellectual capital diukur menggunakan model Value Added Intellectual Coefficient (VAIC) yang dikembangkan oleh Pulic (1998) yang menyediakan standar perhitungan yang mudah serta ukuran dasar yang konsisten. Perhitungan VAIC memiliki beberapa tahap perhitungan, diantaranya :

Value Added

$$
V A=O U T-I N
$$

Keterangan :

$\mathrm{VA}=$ Value Added

OUT $=$ Total penjualan dan pendapatan lain

IN = Beban dan biaya-biaya selain beban karyawan

Value Added Capital Employed

$$
V A C A=V A / C E
$$

Keterangan :

VACA $=$ Value Added Capital Employed

$\mathrm{VA}=$ Value Added

$\mathrm{CE} \quad=$ Dana yang tersedia (ekuitas, laba bersih) 
$V A H U=V A / H C$ II

Keterangan :

VAHU = Value Added Human Capital

$\mathrm{VA} \quad=$ Value Added

$\mathrm{HC}=$ beban tenaga kerja (total gaji, upah dan pendapatan karyawan)

Structural Capital Value Added

$$
S T V A=S C / V A
$$

Keterangan :

$$
\begin{array}{ll}
\text { STVA } & =\text { Structural Capital Value Added } \\
\text { VA } & =\text { Value Added } \\
\text { SC } & =\text { VA }-\mathrm{HC}
\end{array}
$$

Menghitung VAIC, yaitu penjumlahan dari VACA, VAHU, dan STVA dengan rumus sebagai berikut:

$$
V A I C=V A C A+V A H U+S T V A
$$

\section{HASIL DAN PEMBAHASAN}

\section{Analisis Data Statistik Deskriptif}

Analisis statistik deskriptif merupakan teknik analisis data yang bertujuan untuk mendeskripsikan Tabel 1. Hasil Uji Statistik Deskriptif

\begin{tabular}{llrrr}
\hline & & \multicolumn{2}{c}{ Tobin's Q } & \multicolumn{2}{c}{ VAIC } & GCG Score \\
\hline \multirow{2}{*}{$\mathrm{N}$} & Valid & 255 & 255 & 255 \\
\cline { 2 - 5 } & Missing & 0 & 0 & 0 \\
\hline \multirow{2}{*}{ Mean } & 1.7964 & 2.5571 & 23.384 \\
\hline Median & 1.0795 & 2.2833 & 23.500 \\
\hline Std. Deviation & 2.4700 & 2.4633 & 1.8442 \\
\hline Minimum & .3041 & -8.6884 & 19.0 \\
\hline Maximum & 18.8465 & 14.0364 & 29.5 \\
\hline
\end{tabular}

Sumber : Hasil SPSS yang diolah, 2020 
atau memberi gambaran mengenai variabel-variabel penelitian yang dapat dilihat dari nilai minimum, nilai maksimum, nilai rata-rata, dan nilai standar deviasi agar lebih mudah dipahami (Ghozali, 2018). Berikut merupakan hasil analisis deskriptif yang disajikan pada Tabel 1.

Berdasarkan Tabel 1. analisis data statistik deskriptif pada variabel nilai perusahaan yang diukur menggunakan Tobin's Q diperoleh nilai minimum 0.3041 dan nilai maximum 18.8465. Nilai rata-rata 1.7964 yang lebih kecil dari nilai standar deviasi yaitu 2.4700 dapat menunjukkan bahwa penyebaran data nilai perusahaan terdistribusi tidak merata, artinya terdapat perbedaan yang tinggi antara data satu dengan data yang lainnya. Selain itu variabel nilai perusahaan juga memiliki tingkat akurasi yang baik karena nilai rata-rata 1,7964 lebih tinggi dibandingkan dengan nilai median 1.0795 .

Variabel intellectual capital yang diukur menggunakan model Value Added Intellectuaal Coefficient (VAIC) diperoleh nilai minimum -8.6884 dan nilai maximum 14.0364. Nilai rata-rata 2.5571 yang lebih besar dari nilai standar deviasi yaitu 2.4633 dapat menunjukkan bahwa penyebaran data intellectual capital terdistribusi merata, artinya tidak terdapat perbedaan yang tinggi antara data satu dengan data yang lainnya. Selain itu variabel intellectual capital juga memiliki tingkat akurasi yang baik karena nilai rata-rata 2.5571 lebih tinggi dibandingkan dengan nilai median 2.2833.

Variabel Good Corporate Governance (GCG) yang diukur menggunakan GCG Score dengan beberapa subindex diperoleh nilai minimum 19 dan nilai maximum 29.5. Nilai rata-rata 23.384 yang lebih besar dari nilai standar deviasi yaitu 1.8442 dapat menunjukkan bahwa penyebaran data GCG terdistribusi merata, artinya tidak terdapat perbedaan yang tinggi antara data satu dengan data yang lainnya. Selain itu variabel GCG juga memiliki tingkat akurasi yang kurang baik karena nilai rata-rata 23.384 lebih rendah dibandingkan dengan nilai median 23.5.

\section{Uji Asumsi Klasik Model 1 \\ Uji Normalitas}

Tabel 2. Hasil Uji Normalitas

\begin{tabular}{|c|c|c|c|}
\hline \multicolumn{4}{|c|}{ One-Sample Kolmogorov-Smirnov Test } \\
\hline & & & $\begin{array}{l}\text { Unstandardized } \\
\text { Residual }\end{array}$ \\
\hline $\mathrm{N}$ & & & 239 \\
\hline \multirow{2}{*}{ Normal Parameters ${ }^{a, b}$} & Mean & & .0000000 \\
\hline & Std. Deviation & & .50129532 \\
\hline \multirow{3}{*}{$\begin{array}{l}\text { Most Extreme } \\
\text { Differences }\end{array}$} & Absolute & & .073 \\
\hline & Positive & & .073 \\
\hline & Negative & & -.057 \\
\hline Test Statistic & & & .073 \\
\hline Asymp. Sig. (2-tailed) & & & $.003^{\mathrm{C}}$ \\
\hline \multirow{3}{*}{$\begin{array}{l}\text { Monte Carlo Sig. (2- } \\
\text { tailed) }\end{array}$} & Sig. & & $.145^{\mathrm{d}}$ \\
\hline & \multirow{2}{*}{$\begin{array}{l}\text { 99\% Confidence } \\
\text { Interval }\end{array}$} & Lower Bound & .136 \\
\hline & & Upper Bound & .154 \\
\hline
\end{tabular}

Sumber : Data sekunder yang diolah, 2020 
Berdasarkan Tabel 2. hasil One-Sample Kolmogorof_Smirnov test diketahui bahwa nilai signifikansi sebesar $0.145>0.05$ sehingga dapat disimpulkan bahwa nilai residual persamaan model 1 berdistribusi normal, dengan demikian uji normalitas telah terpenuhi.

\section{Uji Autokorelasi}

Tabel 3. Hasil Uji Autokorelasi

\begin{tabular}{lr}
\hline & Runs Test \\
\hline & $\begin{array}{c}\text { Unstandardized } \\
\text { Residual }\end{array}$ \\
\hline Test Value $^{\mathrm{a}}$ & -.08366 \\
\hline Cases $<$ Test Value & 119 \\
\hline Cases $>=$ Test Value & 120 \\
\hline Total Cases & 239 \\
\hline Number of Runs & 127 \\
\hline Z & .843 \\
\hline Asymp. Sig. (2-tailed) & .399 \\
\hline
\end{tabular}

Sumber : Data sekunder yang diolah, 2020

Berdasarkan Tabel 3. hasil Runs test dapat diketahui bahwa nilai Asymp. Sig. (2-tailed) sebesar $0.399>0.05$ sehingga dapat disimpulkan bahwa persamaan model regresi 1 terbebas dari gejala autokorelasi, dengan demikian uji autokorelasi telah terpenuhi.

\section{Uji Heteroskedastisitas}

Tabel 4. Hasil Uji Heteroskedastisitas

\begin{tabular}{lllrr}
\hline & \multicolumn{2}{c}{ Correlations } \\
\hline & & GCG & \multicolumn{2}{c}{$\begin{array}{c}\text { Unstandardized } \\
\text { Residual }\end{array}$} \\
\hline \multirow{4}{*}{$\begin{array}{l}\text { Spearman's } \\
\text { rho }\end{array}$} & GCG & Correlation Coefficient & 1.000 & -.049 \\
\cline { 2 - 5 } & & Sig. (2-tailed) & & .449 \\
\cline { 2 - 5 } & $\mathrm{N}$ & Correlation Coefficient & -.049 & 255 \\
\cline { 2 - 5 } & $\begin{array}{l}\text { Unstandardized } \\
\text { Residual }\end{array}$ & Sig. (2-tailed) & .449 & 1.000 \\
\cline { 3 - 5 } & $\mathrm{N}$ & 239 & 239 \\
\hline
\end{tabular}

Sumber : Data sekunder yang diolah, 2020

Berdasarkan Tabel 4. hasil Rank Spearman test dapat diketahui bahwa nilai signifikansi dari variabel GCG sebesar 0.449 >0.05 sehingga dapat disimpulkan bahwa persamaan model regresi 1 terbebas dari gejala heteroskedastisitas, dengan demikian uji heteroskedastisitas telah terpenuhi. 
JURNAL AKUNTANSI INDONESIA

\section{Uji Asumsi Klasik Model 2 \\ Uji Multikolinieritas}

Tabel 5. Hasil Uji Multikolinieritas

\begin{tabular}{lcccc}
\hline \multirow{2}{*}{ Persamaan } & \multirow{2}{*}{ Variabel } & \multicolumn{2}{c}{ Collinearity Statistic } & \multirow{2}{*}{ Keterangan } \\
\cline { 2 - 4 } & & Tolerance & VIF & \\
\hline \multirow{2}{*}{ Regresi 2 } & VAIC & 0.985 & 1.015 & Bebas Multikolinieritas \\
\cline { 2 - 4 } & GCG & 0.985 & 1.015 & Bebas Multikolinieritas \\
\hline
\end{tabular}

Sumber : Data sekunder yang diolah, 2020

Berdasarkan Tabel 5. menunjukkan bahwa tidak terjadi korelasi antar variabel bebas (independen), hal ini terlihat dari nilai tolerance dari variabel VAIC sebesar $0.985>0.1$ dan nilai VIF sebesar $1.015<10$. Begitu juga pada variabel GCG nilai tolerance sebesar $0.985>0.1$ dan nilai VIF sebesar $1.015<10$. Sehingga dapat disimpulkan bahwa tidak terjadi gejala multikolinieritas pada persamaan regresi, dengan demikian uji multikolinieritas telah terpenuhi.

\section{Uji Normalitas}

Uji Normalitas bertujuan untuk mengetahui apakah dalam model regresi variabel pengganggu atau residual mempunyai distribusi normal atau tidak.

Tabel 6. Hasil Uji Normalitas

\begin{tabular}{|c|c|c|c|}
\hline \multicolumn{3}{|c|}{ One-Sample Kolmogorov-Smirnov Test } & \multirow[b]{2}{*}{$\begin{array}{c}\text { Unstandardized } \\
\text { Residual }\end{array}$} \\
\hline & & & \\
\hline $\mathrm{N}$ & & & 255 \\
\hline \multirow{2}{*}{ Normal Parameters ${ }^{a, b}$} & Mean & & .0000000 \\
\hline & Std. Deviation & & .60805574 \\
\hline \multirow{3}{*}{$\begin{array}{l}\text { Most Extreme } \\
\text { Differences }\end{array}$} & Absolute & & .064 \\
\hline & Positive & & .064 \\
\hline & Negative & & -.028 \\
\hline Test Statistic & & & .064 \\
\hline Asymp. Sig. (2-tailed) & & & $.014^{\mathrm{C}}$ \\
\hline \multirow{3}{*}{$\begin{array}{l}\text { Monte Carlo Sig. (2- } \\
\text { tailed) }\end{array}$} & Sig. & & $.249^{\mathrm{d}}$ \\
\hline & $99 \%$ Confidence & Lower Bound & .238 \\
\hline & Interval & Upper Bound & .260 \\
\hline
\end{tabular}

Sumber : Data sekunder yang diolah, 2020

Berdasarkan Tabel 6. hasil One-Sample Kolmogorof-Smirnov test diketahui bahwa nilai signifikansi sebesar $0.249>0.05$ sehingga dapat disimpulkan ibahwa nilai residual persamaan model 2 berdistribusi normal, dengan demikian uji normalitas telah terpenuhi. 


\section{Uji Autokorelasi}

Tabel 7. Hasil Uji Autokorelasi

\begin{tabular}{lcc}
\hline \multicolumn{3}{c}{ Runs Test } \\
\hline & $\begin{array}{c}\text { Unstandardized } \\
\text { Residual }\end{array}$ \\
\hline Test Value $^{\mathrm{a}}$ & -.05085 \\
\hline Cases $<$ Test Value & 127 \\
\hline Cases $>=$ Test Value & 128 \\
\hline Total Cases & 255 \\
\hline Number of Runs & 133 \\
\hline Z & .565 \\
\hline Asymp. Sig. (2-tailed) & .572 \\
\hline
\end{tabular}

Sumber : Data sekunder yang diolah, 2020

Berdasarkan hasil Runs test pada Tabel 7. diatas diketahui bahwa nilai Asymp. Sig. (2-tailed) sebesar $0.572>0.05$ sehingga dapat disimpulkan bahwa persamaan model regresi 2 terbebas dari gejala autokorelasi, dengan demikian uji autokorelasi telah terpenuhi.

\section{Uji Heteroskedastisitas}

Tabel 8. Hasil Uji Heteroskedastisitas

\begin{tabular}{|c|c|c|c|c|c|}
\hline \multicolumn{6}{|c|}{ Correlations } \\
\hline & & & GCG & VAIC & $\begin{array}{l}\text { Unstandardiz } \\
\text { ed Residual }\end{array}$ \\
\hline \multirow{9}{*}{$\begin{array}{l}\text { Spearman's } \\
\text { rho }\end{array}$} & \multirow{3}{*}{ GCG } & Correlation Coefficient & 1.000 & $.123^{*}$ & -.049 \\
\hline & & Sig. (2-tailed) & & .049 & .438 \\
\hline & & $\mathrm{N}$ & 255 & 255 & 255 \\
\hline & \multirow{3}{*}{ VAIC } & Correlation Coefficient & $.123^{*}$ & 1.000 & .074 \\
\hline & & Sig. (2-tailed) & .049 & & .241 \\
\hline & & $\mathrm{N}$ & 255 & 255 & 255 \\
\hline & \multirow{3}{*}{$\begin{array}{l}\text { Unstand } \\
\text { ardized } \\
\text { Residual }\end{array}$} & Correlation Coefficient & -.049 & .074 & 1.000 \\
\hline & & Sig. (2-tailed) & .438 & .241 & \\
\hline & & $\mathrm{N}$ & 255 & 255 & 255 \\
\hline
\end{tabular}

Sumber : Data sekunder yang diolah, 2020

Berdasarkan Tabel 8., hasil Rank Spearman test dapat diketahui bahwa nilai signifikansi dari variabel GCG sebesar $0.438>0.05$ dan variabel VAIC sebesar $0.241>0.05$ sehingga dapat disimpulkan bahwa persamaan model regresi 2 terbebas dari gejala heteroskedastisitas, dengan demikian uji heteroskedastisitas telah terpenuhi.

Good Corporate Governance dan Intellectual Capital Sebagai Determinan Nilai PerusahaanListiyowati, lin 


\section{Analisis Regresi Linier Berganda Model 1}

Tabel 9. Persamaan Regresi 1

\begin{tabular}{llll} 
& & \multicolumn{3}{c}{ Unstandardized Coefficients } \\
\cline { 2 - 4 } & & B & \multicolumn{2}{c}{ Std. Error } \\
\hline & (Constant) & .438 & .407 \\
\cline { 2 - 4 } & GCG Score & .051 & .017 \\
\hline
\end{tabular}

Sumber : Data sekunder yang diolah, 2020

Berdasarkan Tabel 9. didapatkan model persamaan regresi akhir yang pertama sebagai berikut:

$$
Y A=0.438+0.051+\varepsilon
$$

\section{Uji F}

Tabel 10. Hasil Uji F

\begin{tabular}{llrrrrr}
\hline \multicolumn{1}{l}{ Model } & $\begin{array}{c}\text { Sum of } \\
\text { Squares }\end{array}$ & Df & Mean Square & F & Sig. \\
\hline \multirow{2}{*}{1} & 2.212 & 1 & 2.212 & 8.765 & $.003^{\mathrm{b}}$ \\
\cline { 2 - 6 } & Regression & 59.809 & 237 & .252 & & \\
\cline { 2 - 6 } & Residual & 62.021 & 238 & & \\
\hline
\end{tabular}

Sumber : Data sekunder yang diolah, 2020

Berdasarkan Tabel 10., dapat dilihat bahwa nilai F sebesar 8.765 dengan nilai signifikansi $0.003<0.05$. Hal ini dapat disimpulkan bahwa variabel GCG secara simultan berpengaruh signifikan terhadap variabel dependen yakni intellectual capital yang diproksikan dengan VAIC.

\section{Uji Koefisien Determinasi $\left(\mathbf{R}^{2}\right)$}

Tabel 11. Hasil Uji Koefisien Determinasi $\left(\mathrm{R}^{2}\right)$

\begin{tabular}{llrrr} 
Model & $\mathrm{R}$ & R Square & $\begin{array}{c}\text { Adjusted } \mathrm{R} \\
\text { Square }\end{array}$ & $\begin{array}{c}\text { Std. Error of the } \\
\text { Estimate }\end{array}$ \\
\hline 1 & $.189^{\mathrm{a}}$ & .036 & .032 & .50235 \\
\hline
\end{tabular}

Sumber : Data sekunder yang diolah, 2020

Berdasarkan Tabel 11., dapat dilihat bahwa model persamaan regresi 1 nilai $R$ square $\left(R^{2}\right)$ menunjukkan pada angka $0.036 \times 100 \%=3.6 \%$. Hal ini dapat disimpulkan bahwa kontribusi variabel GCG terhadap IC adalah $3.6 \%$ sedangkan $96.4 \%$ dipengaruhi faktor lain.

\section{Uji t}


Tabel 12. Hasil Uji t

\begin{tabular}{|c|c|c|c|c|c|c|}
\hline & \multirow{2}{*}{ Model } & \multicolumn{2}{|c|}{$\begin{array}{l}\text { Unstandardized } \\
\text { Coefficients }\end{array}$} & \multirow{2}{*}{$\begin{array}{c}\begin{array}{c}\text { Standardized } \\
\text { Coefficients }\end{array} \\
\text { Beta }\end{array}$} & \multirow{2}{*}{$\mathrm{t}$} & \multirow{2}{*}{ Sig. } \\
\hline & & B & Std. Error & & & \\
\hline \multirow{2}{*}{1} & (Constant) & .438 & .407 & & 1.077 & .283 \\
\hline & GCG Score & .051 & .017 & 189 & 2.961 & .003 \\
\hline
\end{tabular}

Sumber : Data sekunder yang diolah, 2020

Berdasarkan Tabel 12., model persamaan regresi 1 dapat diketahui bahwa variabel good corporate governance diperoleh sebesar 2.961 dengan tingkat signifikansi $0.003<0.05$ dan koefisien $\beta$ sebesar 0.189. Dengan demikian berarti hipotesis yang menyatakan GCG berpengaruh positif signifikan terhadap IC diterima.

\section{Uji Regresi Linier Berganda Model 2}

\begin{tabular}{|c|c|c|c|}
\hline & & \multicolumn{2}{|c|}{ Unstandardized Coefficients } \\
\hline \multicolumn{2}{|c|}{ Model } & B & Std. Error \\
\hline \multirow{3}{*}{1} & (Constant) & -2.743 & .488 \\
\hline & VAIC & .119 & .016 \\
\hline & GCG Score & .114 & .021 \\
\hline
\end{tabular}

Sumber : Data sekunder yang diolah, 2020

Berdasarkan Tabel 13., didapatkan model persamaan regresi akhir yang kedua sebagai berikut:

$$
Y=-2,743+0,119+0,114+\varepsilon
$$

Uji F

Tabel 14. Hasil Uji F

\begin{tabular}{|c|c|c|c|c|c|c|}
\hline Model & & $\begin{array}{l}\text { Sum of } \\
\text { Squares }\end{array}$ & Df & Mean Square & $\mathrm{F}$ & Sig. \\
\hline \multirow{3}{*}{1} & Regression & 36.871 & 2 & 18.435 & 49.469 & $.000^{b}$ \\
\hline & Residual & 93.912 & 252 & .373 & & \\
\hline & Total & 130.783 & 254 & & & \\
\hline
\end{tabular}

Sumber : Data sekunder yang diolah, 2020

Berdasarkan Tabel 14., dapat dilihat bahwa nilai F sebesar 49.469 dengan nilai signifikansi $0.000<0.05$. Hal ini dapat disimpulkan bahwa variabel GCG dan IC yang diproksi dengan VAIC secara simultan berpengaruh signifikan terhadap variabel dependen yakni nilai perusahaan yang diproksi dengan Tobin's Q. 


\section{Uji Koefisien Determinasi $\left(\mathbf{R}^{2}\right)$}

Tabel 15. Hasil Uji Koefisien Determinasi $\left(R^{2}\right)$

\begin{tabular}{|c|c|c|c|c|}
\hline Model & $\mathrm{R}$ & R Square & $\begin{array}{l}\text { Adjusted R } \\
\text { Square }\end{array}$ & $\begin{array}{l}\text { Std. Error of } \\
\text { the Estimate }\end{array}$ \\
\hline 1 & $.531^{\mathrm{a}}$ & .282 & .276 & 61046 \\
\hline
\end{tabular}

Sumber : Data sekunder yang diolah, 2020

Berdasarkan Tabel 15., dapat dilihat model persamaan regresi 2 nilai $R$ square $\left(R^{2}\right)$ menunjukkan pada angka $0.282 \times 100 \%=28.2 \%$. Hal ini dapat disimpulkan bahwa kontribusi variabel GCG dan IC terhadap nilai perusahaan adalah $28.2 \%$ sedangkan $71.8 \%$ dipengaruhi faktor lain.

Uji t

Tabel 16. Hasil Uji t

\begin{tabular}{|c|c|c|c|c|c|c|}
\hline \multirow[b]{2}{*}{ Model } & & \multicolumn{2}{|c|}{$\begin{array}{l}\text { Unstandardized } \\
\text { Coefficients }\end{array}$} & \multirow{2}{*}{$\begin{array}{c}\text { Standardized } \\
\text { Coefficients } \\
\text { Beta } \\
\end{array}$} & \multirow[b]{2}{*}{$\mathrm{t}$} & \multirow[b]{2}{*}{ Sig. } \\
\hline & & $\mathrm{B}$ & Std. Error & & & \\
\hline \multirow{3}{*}{1} & (Constant) & -2.743 & .488 & & -5.625 & .000 \\
\hline & VAIC & .119 & .016 & .409 & 7.600 & .000 \\
\hline & GCG Score & .114 & .021 & 293 & 5.442 & .000 \\
\hline
\end{tabular}

Sumber : Data sekunder yang diolah, 2020

Berdasarkan Table 16., dalam model regresi 2 dapat diketahui bahwa pengujian secara parsial pada variabel intellectual capital yang diproksikan dengan Value Added Intellectual Coefficient (VAIC) diperoleh sebesar 7.600 dengan tingkat signifikansi $0.000<0.05$ dan koefisien $\beta$ sebesar 0.409. Dengan demikian berarti hipotesis yang menyatakan IC berpengaruh positif signifikan terhadap nilai perusahaan diterima.

Pengujian secara parsial pada variabel good corporate governance diperoleh sebesar 5.442 dengan tingkat signifikansi $0.000<0.05$ dan koefisien $\beta$ sebesar 0.293 . Dengan demikian berarti hipotesis yang menyatakan GCG berpengaruh positif signifikan terhadap nilai perusahaan diterima.

\section{Uji Sobel}

Uji Sobel digunakan untuk mengetahui apakah hubungan yang melalui variabel mediasi secara signifikan mampu sebagai mediator dalam hubungan tersebut. Besarnya standard error (Sab) pengaruh tidak langsung dapat dihitung sebagai berikut : 


$$
\begin{aligned}
& S a b=\sqrt{b^{2} S a^{2}+a^{2} S b^{2}+S a^{2} S b^{2}} \\
& S a b=\sqrt{(0,119)^{2}(0,017)^{2}+(0,051)^{2}(0,016)^{2}+(0,017)^{2}(0,016)^{2}} \\
& S a b=\sqrt{0,000004093+0,000000666+0,000000074} \\
& S a b=\sqrt{0,000004832} \\
& S a b=0,002198265
\end{aligned}
$$

Berdasarkan hasil perhitungan Sab dapat digunakan untuk menguji signifikansi pengaruh tidak langsung dengan menghitung nilai t statistik dari koefisien perkalian ab dengan perhitungan sebagai berikut:

$$
t=\frac{a b}{S a b}=\frac{0,051 \times 0,119}{0,002198265}=\frac{0,006069}{0,002198265}=2,76
$$

Berdasarkan perhitungan $t$ hitung diatas, diperoleh nilai $t=2.76$ yang lebih besar dari nilai $t$ tabel 1.96 dengan tingkat signifikansi 0.05 maka dapat disimpulkan bahwa koefisien mediasi 0.006069 signifikan dan berarti ada pengaruh mediasi intellectual capital dalam hubungan pengaruh good corporate governance terhadap nilai perusahaan.

\section{PEMBAHASAN}

\section{Pengaruh Good Corporate Governance terhadap Intellectual Capital}

Hasil dari penelitian dapat dikatakan bahwa variabel good corporate governance berpengaruh positif dan signifikan terhadap intellectual capital yang ditunjukkan dengan diperolehnya nilai signifikansi sebesar 0.003 yang lebih kecil dari 0.05 . GCG berfungsi sebagai pengendali dan pengawas pihak pengelola perusahaan dalam menjalankan kegiatan operasional termasuk dalam mengelola IC yang terdiri dari tiga komponen yaitu human capital, structural capital, dan relational capital agar menghasilkan karyawan yang berkualitas dan perkembangan teknologi informasi yang lebih baik. Dengan adanya penerapan GCG akan mendorong pihak pengelola perusahaan untuk menciptakan, mengelola, dan meningkatkan IC yang dimiliki perusahaan. Sehingga perusahaan mampu menciptakan nilai, keunggulan kompetitif, dan karakteristik unik bagi perusahaan. Hasil ini sejalan dengan penelitian yang dilakukan oleh Handoko \& Fuad (2013); Wasisto \& Yuyetta (2016) serta Noventa (2016) yang menyatakan bahwa Good Corporate Governance berpengaruh positif terhadap intellectual capital. 


\section{Pengaruh Intellectual Capital terhadap Nilai Perusahaan}

Hasil dari penelitian dapat dikatakan bahwa variabel intellectual capital berpengaruh positif dan signifikan terhadap nilai perusahaan yang ditunjukkan dengan diperolehnya nilai signifikansi sebesar 0.000 yang lebih kecil dari 0.05. intellectual capital yang dimiliki perusahaan merupakan salah satu aspek penilaian ketika para investor akan menanamkan sahamnya. Apabila perusahaan memiliki kemampuan yang tinggi dalam mengelola intellectual capital nya dengan baik akan memberi gambaran kepada investor mengenai prospek kerja yang baik di masa yang akan datang. Selain itu perusahaan akan mampu meningkatkan kompetensi dan keunggulan kompetitifnya dalam kegiatan operasionalnya sehingga laba perusahaan mengalami peningkatan. Laba perusahaan yang terus meningkat akan menarik para investor karena deviden yang diterima juga meningkat dan akan berdampak pada nilai perusahaan yang tinggi. Hasil ini sejalan dengan penelitian yang dilakukan oleh Suparno \& Ramadini (2017); Maryanto (2017); serta Arini \& Musdholifah (2018) yang menyatakan bahwa intellectual capital berpengaruh positif terhadap nilai perusahaan.

\section{Pengaruh Good Corporate Governance terhadap Nilai Perusahaan}

Hasil dari penelitian dapat dikatakan bahwa variabel good corporate governance berpengaruh positif signifikan terhadap nilai perusahaan yang ditunjukkan dengan diperolehnya nilai signifikansi sebesar 0.000 yang lebih kecil dari 0.05 . Penerapan good corporate governance berfungsi untuk menumbuhkan pengendalian yang baik dan mencegah adanya penyimpangan yang dilakukan pihak pengelola perusahaan dalam menjalankan kegiatan operasional sehingga perusahaan lebih sehat. Selain itu dengan penerapan GCG diharapkan perusahaan akan memiliki kinerja yang baik sehingga dapat memberikan keuntungan dan kemakmuran bagi para pemegang saham perusahaan. Dengan itu perusahaan akan dianggap memiliki nilai yang berharga dan memiliki prospek yang baik di masa yang akan datang. Hasil ini sejalan dengan penelitian yang dilakukan oleh oleh Herawaty (2008); Randy \& Juniarti (2013); Gwenda \& Juniarti (2013); Muryati \& Suardikha (2014); serta Maryanto (2017) yang menyatakan bahwa intellectual capital berpengaruh positif terhadap nilai perusahaan.

\section{Pengaruh Good Corporate Governance terhadap Nilai Perusahaan melalui Intellectual Capital}

Hasil dari penelitian dapat dikatakan bahwa variabel intellectual capital mampu memediasi hubungan antara good corporate governance dengan nilai perusahaan yang ditunjukkan dengan diperolehnya nilai $t$ hitung sebesar 2.76 yang lebih besar dari nilai t tabel 1.96 dengan tingkat signifikansi 0.05 . Dengan adanya penerapan good corporate governance pihak manajer akan dituntut untuk mampu mengelola perusahaan dengan memanfaatkan intellectual capital yang dimiliki secara optimal guna meningkatkan keunggulan kompetitif perusahaan dan pada akhirnya akan meningkatkan nilai perusahaan. Pengembangan intellectual capital dapat memberikan keunggulan kompetitif yang berkelanjutan bagi perusahaan karena sifatnya yang berharga dan sulit ditiru sehingga berpengaruh terhadap kapasitas dan kefektifan perusahaan dalam menghasilkan nilai tambah dimana para investor akan memberikan penilaian yang lebih baik terhadap perusahaan dengan berinvestasi lebih tinggi. 


\section{PENUTUP}

\section{Kesimpulan}

Good orporate governance berpengaruh positif dan signifikan terhadap intellectual capital. Kondisi ini terjadi karena dengan penerapan good corporate governance akan mendorong manajemen untuk menciptakan, mengelola, dan meningkatkan intellectual capital yang dimiliki perusahaan.

Intellectual capital berpengaruh positif dan signifikan terhadap nilai perusahaan. Kondisi ini terjadi karena dengan intellectual capital yang tinggi mampu memberikan nilai tambah, keunggulan kompetitif, dan karakteristik yang unik bagi perusahaan sehingga para investor tertarik untuk berinvestasi dan nilai perusahaan meningkat.

Good corporate governance berpengaruh positif dan signifikan terhadap nilai perusahaan. Adanya good corporate governance dalam sebuah perusahaan mampu melakukan pengawasan terhadap manajemen dalam menjalankan kegiatan operasional perusahaan, sehingga kinerja menjadi baik dan dapat memberikan keuntungan dan kemakmuran bagi para investor.

Intellectual capital mampu memediasi pengaruh good corporate governance terhadap nilai perusahaan. Dengan good corporate governance yang diterapkan dalam perusahaan maka pihak manajemen akan memaksimalkan pengelolaan intellectual capital yang akan memberikan nilai lebih pada perusahaan dan meningkatkan keunggulan kompetitif sehingga nilai perusahaan ikut meningkat.

\section{Keterbatasan}

Pengukuran variabel intellectual capital dengan metode VAIC yang hanya mengolah informasi dari laporan keuangan perusahaan saja dapat menimbulkan perbedaan persepsi mengenai klasifikasi biaya pembentuk VAIC.

Besarnya kemampuan pengaruh good corporate governance dan intellectual capital terhadap nilai perusahaan hanya menunjukkan angka $28.2 \%$ yang berarti masih ada $71.8 \%$ variabel diluar penelitian yang dapat mempengaruhi nilai perusahaan yang tidak diteliti dalam penelitian ini. Uji statistik deskriptif pada variabel intellectual capital diperoleh rata-rata 2.5571 yang berarti intellectual capital masih rendah.

\section{Saran}

Penelitian selanjutnya dapat menggunakan metode pengukuran intellectual capital yang lain sehingga hasilnya dapat dijadikan perbandingan dengan penelitian yang menggunakan metode VAIC. Contoh pengukuran intellectual capital yang dapat dipakai diantaranya Calculated Intangible Value (Stewart, 1997); The Value Explorer (Andriessen, 2005); dan Intellectual Capital Dynamic Value (IC-dVAL) (Bounfour, 2003).

Penelitian selanjutnya disarankan untuk menambah variabel lain terkait nilai perusahaan diantaranya share ownership dan Corporate Social Responsibility (CSR). Share ownership merupakan peresentase dari kepemilikan saham dalam sebuah perusahaan, dengan kepemilikan saham yang tinggi akan membuat persepsi investor terhadap perusahaan itu baik sehingga investor dapat mengontrol perusahaan dengan baik dan akan meningkatkan nilai perusahaan. Dengan adanya penerapan CSR sebagai bentuk pertanggungjawaban 
perusahaan dalam memperbaiki kesenjangan sosial serta kerusakan lingkungan akibat dari kegiatan operasionalnya dapat meningkatkan image perusahaan menjadi lebih baik. Sehingga para investor akan lebih tertarik untuk menanamkan sahamnya dan akan berpengaruh pada nilai perusahaan yang semakin meningkat.

Perusahaan diharapkan mampu meningkatkan investasi jangka panjang berupa investasi intellectual capital dengan cara mengadakan pelatihan dan pendidikan untuk para karyawan agar mampu mengasah segala potensi dan kemampuan yang dimiliki, dan akan memberikan berbagai inovasi baru yang kreatif. Dengan itu produktivitas perusahaan akan meningkat dan memiliki keunggulan kompetitif tersendiri sehingga mampu menghasilkan nilai perusahaan yang tinggi.

\section{DAFTAR PUSTAKA}

Alfinur, A. (2016). Pengaruh Mekanisme Good Corporate Governance (Gcg) Terhadap Nilai Perusahaan Pada Perusahaan Yang Listing Di Bei. Jurnal Ekonomi MODERNISASI, 12(1), 44. https://doi.org/10.21067/jem. v12i1.1178

Andriessen, D. (2005). Implementing The KPMG Value Explorer. Journal of Intellectual Capital, 6(5), 1-18.

Arini, Y., \& Musdholifah, M. (2018). Pengaruh Intellectual Capital Dan Good Corporate Governance Terhadap Nilai Perusahaan Melalui Kinerja Keuangan (Studi Pada Perusahaan Subsektor Perbankan Yang Listing Di Bei Periode 2013-2016). Jurnal IImu Manajemen (JIM), 6(3), 227-240.

Awaliyah, N., \& Safriliana, R. (2017). Pengaruh Intellectual Capital Pada Nilai Perusahaan Perbankan. Jurnal Reviu Akuntansi Dan Keuangan, 6(2), 913-922. https://doi.org/10.22219/jrak.v6i2.03

Black, B. S., Jang, H., \& Kim, W. (2006). Does corporate governance predict firms' market values? Evidence from Korea. Journal of Law, Economics, and Organization, 22(2), 366-413. https://doi.org/10.1093/jleo/ewj018

Bounfour, A. (2003). The IC-dVAL approach. Journal of Intellectual Capital, 4(3), 396-413.

Darmadji, T., \& Fakhruddin, H. M. (2001). Pasar Modal di Indonesia. Salemba Empat.

Ghozali, I. (2018). Aplikasi Analisis Multivariate dengan Program IBM SPSS 25. Universitas Diponegoro.

Gwenda, Z., \& Juniarti. (2013). Pengaruh Penerapan Good Corporate Governance (GCG) Pada Variabel Share Ownership, Debt Ratio, dan Sektor Industri Terhadap Nilai Perusahaan. Business Accounting Review, 1(2), 137-147.

Handoko, S., \& Fuad. (2013). Analisis Hubungan Antara Corporate Governance, Intellectual Capital , Dan Kinerja Perusahaan. 2(4), 1-11.

Hartati, N. (2014). INTELLECTUAL CAPITAL DALAM MENINGKATKAN DAYA SAING: SEBUAH TELAAH LITERATUR. Jurnal Etikonomi, 13(1), 51-68.

Herawaty, V. (2008). Peran Praktek Corporate Governance Sebagai Moderating Variable dari Pengaruh Earnings Management Terhadap Nilai Perusahaan. Simposium Nasional Akuntansi XI.

Indah, N., \& Handayani, S. (2017). Pengaruh Corporate Governance Terhadap Intellectual Capital Disclosure. Diponegoro Journal of Accounting, 6(3), 471-478. 
Jensen, M. C., \& Meckling, W. . (1976). THEORY OF THE FIRM: MANAGERIAL BEHAVIOR, AGENCY COSTS AND OWNERSHIP STRUCTURE Michael. Journal of Financial Economics 3, 3, 305-360. https://doi. org/10.1177/0018726718812602

Juwita, R., \& Angela, A. (2016). Pengaruh Intellectual Capital Terhadap Nilai Perusahaan Pada Perusahaan Indeks Kompas 100 Di Bursa Efek Indonesia. Jurnal Akuntansi, 8(1), 1-15.

Maryanto, H. K. (2017). PENGARUH INTELLECTUAL CAPITAL DAN GOOD CORPORATE GOVERNANCE TERHADAP NILAI PERUSAHAAN DENGAN KINERJA KEUANGAN SEBAGAIVARIABEL INTERVENING PADA PERUSAHAAN MANUFAKTUR DI BURSA EFEK INDONESIA TAHUN 2011-2014. JOM Fekon, 4(1), 1598-1612.

Muryati, N., \& Suardikha, I. (2014). Pengaruh Corporate Governance Pada Nilai Perusahaan. E-Jurnal Akuntansi, 9(2), 425-429.

Mutmainah. (2015). Analisis Good Corporate Governance Terhadap Nilai Perusahaan. E-Journal Stiedewantara, Vol. X(No.2, Oktober), pp: 1-15. http://ejournal.stiedewantara.ac.id

Nizar, A. S., \& Anwar, M. K. (2015). Pengaruh Pembiayaan Jual Beli, Pembiayaan Bagi Hasil Dan Intellectual Capital Terhadap Kinerja Keuangan Bank Syariah. AKRUAL: Jurnal Akuntansi, 6(2), 130. https://doi.org/10.26740/ jaj.v6n2.p130-146

Noventa, O. C. (2016). PENGARUH CORPORATE GOVERNANCE DAN OWNERSHIP STRUCTURE TERHADAP INTELLECTUAL CAPITAL PERFORMANCE.

Penrose, E. (1959). The Theory of the Growth of the Firm. Basil Backwell.

Pradono, N. S. H., \& Widowati, E. H. (2016). Pengaruh Komisaris Asing, Direktur Asing Dan Kepemilikan Asing Terhadap Kinerja Intellectual Capital. Kinerja, 20(2), 132. https://doi.org/10.24002/kinerja.v20i2.840

Pulic. (1998). Measuring the performance of intellectual potential in knowledge economy.

Randy, V., \& Juniarti. (2013). Pengaruh penerapan good corporate governance terhadap nilai perusahaan yang terdaftar di BEI 2007-2011. Business Accounting Review, 1(2), 306-318. http://publication.petra.ac.id/ index.php/akuntansi-bisnis/article/view/1053/947

Sunarsih, N. M., \& Mendra, N. P. Y. (2019). Pengaruh Modal Intelektual terhadap Nilai Perusahaan dengan Kinerja Keuangan sebagai Variabel Intervening pada Perusahaan yang Terdaftar di BEl. Journal of Chemical Information and Modeling, 53(9), 1689-1699.

Suparno, S., \& Ramadini, R. (2017). Pengaruh Intellectual Capital dan Earning PerShare terhadap Nilai Perusahaan (Studi Empiris pada Perusahaan LQ45 yang Terdaftar di Bursa Efek Indonesia Periode 2010-2014). Jurnal Manajemen Dan Keuangan Unsam, 6(1), 710-718.

Verawaty, Merina, I. C., \& Lastari, S. A. (2017). PENGARUH INTELLECTUAL CAPITAL, EARNINGS MANAGEMENT, TAX AVOIDANCE TERHADAP NILAI PERUSAHAAN DENGAN GCG SEBAGAI PEMODERASI. Jurnal Ilmiah $M B i A, 16(2), 79-94$.

Wasisto, A. K., \& Yuyetta, E. N. A. (2016). Pengaruh Corporate Governance Terhadap Kinerja Perusahaan: Intellectual Capital sebagai Variabel Intervening. Diponegoro Journal of Accounting, 5(2), 1-15.

Good Corporate Governance dan Intellectual Capital Sebagai Determinan Nilai PerusahaanListiyowati, lin 